Luís Otávio Farias 1

Clarice M elamed 1

\section{Segmentação de mercados da assistência à saúde no Brasil}

\author{
$M$ arket shares in the Brazilian health sector
}

Abstract The current paper presents in its first part a theoretical framework for analyzing the main market failures in the health sector followed by a general evaluation of the private health sector in OCDE countries and a comparative approach to the Brazilian case. In the second part, there is a brief historical of the private health sector in Brazil since the seventies and also some inferences are drawn from Pnad - IBGE data that allow a picture of private insurance consumers.

Key words Private insurance plans, Supplemental health, $M$ arket failures, $H$ ealth supply and demand
Resumo 0 artigo analisa a dimensão e segmentação do mercado supletivo de assistência à saúde no Brasil e o perfil dos seus segurados. $\mathrm{N}$ a primeira parte, destaca alguns el ementos conceituais necessári os à compreensão das características do mercado em saúde. Analisa brevemente a dimensão e 0 papel do setor privado de saúde em países membros da O rganização para Cooperação e D esenvolvimento Econômico (OCDE) e compara com caso brasileiro. Em seguida, realiza um breve histórico do setor supletivo de saúde no Brasil e, por fim, apresenta uma análise do perfil dos segurados, tendo por base os microdados da Pesquisa $\mathrm{N}$ acional de Amostra por Domicílio de 1998 (Pnad/IBGE).

Palavras-chave Planos de saúde, Saúde suplementar, Fal has de mercado, O ferta e demanda em saúde
1 Escola $\mathrm{N}$ acional de Saúde Pública. Departamento de Ciências Sociais. Fiocruz. Rua Leopoldo Bulhões 1480, 9o andar, $M$ anguinhos, 21041-210, Rio de Janeiro RJ.farias@ensp.fiocruz.br 


\section{Introdução}

0 presente artigo foi escrito com o objetivo de analisar a dimensão de mercado supletivo de assistência à saúde no Brasil e o perfil dos seus segurados, destacan do alguns el ementos conceituais necessários à compreensão das características do mercado, em sentido lato, quando se trata da produção de bens e serviços relacionados à saúde.

Os princi pais concei tos são apresentados em paralelo a um pequeno levantamento de como coexistem o setor público e privado em saúde hoje entre os países-membros da O rganização para Cooperação e Desenvolvimento Econômico (OCDE) - ealguns outros países não pertencentes a organização. Construímos um quadro básico de referências a partir dos modelos em vigor para, então, analisar a evolução recente da segmentação desse mercado no caso brasileiro dos anos 90 .

Os dados do suplemento especial da Pnad-98 foram utilizados para caracterizar a dimensão e o perfil dos beneficiários de planos privados de saúde no Brasil. Por meio de análise estatística exploratória pode-se responder que função o setor privado de saúde tem cumprido no país, seja na perspectiva de complementação das atividades desempen hadas pelo SUS, seja dirigido à especial ização de clientelas próprias. A análise dos dados permite, também, qualificar os segurados do setor supletivo, propiciando uma melhor compreensão dos elementos que asseguram a formação dessa clientela.

\section{Características do setor saúde}

Arrow (1963), em trabal ho considerado clássico sobre o assunto, define que o objeto do estudo da saúde em termos macroeconômicos está relacionado à indústria de cuidados médicos; mais precisamente, refere-se ao complexo de serviços centrados no médico, grupos privados de atenção à saúde, hospitais e saúde pública.

A pesar de a definição deixar claro qual o espaço de mercado reservado ao setor saúde strito sensu, reabre o debate sobre sua especificidade. U ma das principais características do mercado de serviços de saúde é de que parte dos bens aí produzi dos são considerados bens públicos e/ ou meritórios.

Define-se bens públicos como aqueles que, em geral, o Estado deve provê em função de suas externalidades, verificadas sempre que empresas ou pessoas impõem custos ou benefícios a outros, sem que estes recebam qualquer indenização ou efetuem o devido pagamento e assim não há interesse privado em fornecê-los. Já a definição de bens meritórios está associada a valores históricos, culturais e políticos partilhados por determinado grupo social ou até mesmo por uma nação, a partir dos quais coletivamente são estabelecidos fluxos de redistribuiçãa de recursos entre diferentes estratos da sociedade. A história de estruturação dos estados de bem-estar social foi em grande parte alicerçada com base na necessidade de provisão, por parte dos governos, de serviços de educação, saúde, assistência social e outros, a maior parte deles, podendo enquadrar-se na categoria de bens meritórios.

Além das dificuldades de operacionalizar o equilíbrio entre oferta e procura visando à inclusão universal da população, a al ocação de recursos no setor saúde envolve escol has e dificuldades específicas e mais complexas. A alocação não pode ser baseada somente no custo-efetividade, que focaliza a eficiência, mas ignora a eqüidade. A incerteza associada ao risco financeiro potencial, gerado pela ocorrência de doenças graves, legitima a demanda por subsídios ou seguro público.

Seguros contra problemas de saúde apresentam características próprias relacionadas a várias formas de fal has de mercado - market failures - (Arrow, 1985). Entre elas, podese citar risco moral (moral hazard), ou seja, situações nas quais o seguro social ou privado atua como um fundo de financiamento coletivo ao consumo de serviços de saúde, estimulando o consumo dos que pagam menos eque teriam menos acesso aos serviços, caso tivessem de pagá-los a partir de sua própria renda. Em decorrência, indivíduos que participam com igual contribuição no financiamento usufruem de forma diferenciada dos serviços ofertados.

Quando várias seguradoras que atuam segundo as regras de mercado maximizando lucro competem para vender planos, tende a ocorrer a seleção adversa (adverse selection) e a seleção de risco (risk-selection). Ambas comprometem seriamente a eficiente operação dos mercados de seguro. 0 primeiro se refere à sel eção de potenciais compradores que não interessaria às empresas terem como 
clientes. Fundamentalmente encontra-se associado ao perigo de incorporar como clientes indivíduos cujos tratamentos custarão mais do que em média a seguradora está disposta a financiar. Com o objetivo de protegerem-se da combinação de planos baratos e riscos potenciais al tos, as seguradoras investem na seleção de risco: gastam mais em administração, criando barreiras à inscrição de indivíduos com potenciais problemas de saúde ou idosos.

A seleção adversa e o risco moral emergem em um contexto em que consumidores e seguradoras possuem apenas informação incompleta, o que também acarreta falha de mercado à medida que é condição necessária para competição perfeita que compradores e vendedores possuam informação completa. U ma dificuldade adicional corresponde à informação assimétrica (asymmetry information), isto é, informação disponível somente a um dos lados do mercado. Por exemplo, consumidores que conheçam seus riscos de saúde têm um incentivo para omiti-los das seguradoras para evitar mensalidades muito altas. As seguradoras, em contraste, geral mente conhecem mais sobre riscos médios e custos da assistência do que os consumidores; a ignorância dos consumidores nesses assuntos também pode conduzir à in eficiência.

Em resumo, como conseqüência dessas faIhas de mercado, na ausência de regulação e existindo companhias seguradoras que atuam na forma de terceiro pagador, aqueles com condições crônicas ou altos riscos de saúde serão sub-segurados. Além disso, os custos administrativos serão mais el evados do que os necessários devido aos esforços das seguradoras de filtrar riscos e processar reclamações pelas quais nem o provedor nem o consumidor estão dispostos a se responsabilizar. É nesse sentido que o "mercado não funciona" na atenção à saúde. Contudo, essas fal has se detectam predominantemente no mercado de seguros de saúde, e não necessariamente no mercado de saúde como um todo.

0 debate sobre o papel dos setores público e privado na saúde se organiza teoricamente em torno de como e em que profundidade ocorrem as fal has de mercado. Estas, como uma noção econômica, se referem a possíveis desencontros ou desequilíbrios entre o que 0 mercado oferta e o que consumidores racionais bem informados possam demandar.

No entanto, a concepção teórica está sujei- ta a exceções quando se trata de situações de pobreza, definida, neste caso, pela existência de pessoas que não apresentam condições para pagar pelos mais simples serviços de saú de ou uma adequada parcela de seguro. Essas situações tornariam necessariamente mais amplas as funções do Estado. A falta de condições para acessar serviços médicos não é muito diferente de outros tipos de carência em relação às necessidades mais básicas que pode ser tecnicamente compensadas por meio de transferências e subsídios em espécie ou suplementação de renda. M ais uma vez - o caso da saúde é excepcional - o risco de um grupo populacional necessitar de tratamentos de alto custo pode tornar mais eficiente o subsídio ao seguro do que a transferência de renda, no caso da ausência de serviços públicos com cobertura universal.

\section{0 papel do Estado}

Entre as agências internacionais, há um certo consenso quanto a um papel genérico que 0 Estado deva desempenhar na área da saúde. Aceita-se a idéia de que os governos seriam responsáveis pela criação de instituições que financiem diretamente os serviços de saúdee a distribuição do risco. No entanto, a situação combinada em que o mercado e o governo atingem maior eficiência varia em função da forma como são financiadas essas instituições, assim como, em que circunstâncias se dá a provisão dos serviços. Situações extremadas são consideradas igualmente ineficientes, ou seja, a existência apenas de seguro privado ou a provisão pública exclusiva de serviços. N ão há um modelo que combine as duas formas considerado ótimo.

De uma maneira geral, o mercado privado traz para o setor a questão da eficiência, enquanto o governo seria responsável por uma distribuição eqüitativa de bens de saúde essenciais. A forma de alocação de recursos está diretamente relacionada à efeti vidade de sua aplicação. Se o sistema é administrado pelo governo por meio de prestadores públicos e/ou privados, o orçamento é transferido a regiões ou programas de saúde específicos. No caso de serem utilizadas formas de seguro social ou privado, os recursos são alocados por tipos de serviços correspondentes a pacotes específicos de benefícios.

Há um relativo consenso sobre as ativida- 
des básicas a serem desempenhadas pelo Estado: (1) financiar e prover publicamente bens meritórios como educação para a saúde, imunização, atenção materno-infantil; (2) subsidiar a atenção primária e serviços hospitalares para os pobres; (3) estabelecer seguro nacional ou regional para o setor formal de trabal hadores e suas famílias; (4) regular as falhas do mercado e monitorar sua performance; (5) educar o público para que esteja informado sobre os serviços de saúde.

\section{0 mix público e privado}

Em grande parte dos casos, éa forma como o Estado está organizado para produzir os serviços de saúde que dá os contornos ea dimensão do setor privado. Este tende a emergir quando ocorre uma percepção coletiva de que o sistema público oferece serviços de baixa qualidade, não permite possibilidade de escoIha do provedor ou por cobrir apenas al guns tipos de serviços. Em geral, o papel do seguro privado pode ser de três tipos:

1) cobertura de indivíduos que são inel egíveis ao seguro público. N este caso, o principal exemplo são os EU A onde apenas uma parte da população é el egível (idosos e pobres);

2) cobertura de indivíduos que optam por retirar-se do programa de seguro público universal, por exemplo, a Alemanha;

3) cobertura suplementar de serviços coexistindo com um sistema público universal, por exemplo, Reino Unido e Brasil.

No caso dos países da OCDE, o espectro de combinações possíveis que trata do finan- ciamento da saúde e tipos de prestadores apareceno quadro 1.

De forma geral, a adesão ao seguro privado nesse grupo de países, com exceção dos EUA, cumpre a função de complementar 0 sistema público de saúde, oscilando a cobertura da população entre 45\% na Austrália e 9\% no Reino U nido (Chollet \& Lewis, 1997). Seu formato varia de país a país, incluindo serviços especializados não cobertos pelo setor público, taxas extras de consultas e hospitalização que excedem o pagamento efetuado através de credenciamento público, ou indivíduos que optem por estar fora do sistema público, como éo caso da Alemanha.

O seguro privado de saúde raramente é a principal fonte de financiamento dos serviços no setor. Atua como sistema suplementar, crescen do em conseqüência da cobertura de segmentos não incluídos pelo seguro social ou pacote básico de benefícios. Em outros casos atua adicionalmente aos serviços financiados pelo sistema público existente. $N$ esses países, os planos de seguro privado com freqüência excluem doenças crônicas ou as que exigem tratamentos prolongados e custosos; apresentam baixo teto de benefícios ( em termos de número de dias de hospitalização ou dispêndio total).

Entre os países mais pobres, que não pertencem à $O C D E$, o percentual médio de adesão da população ao seguro privado é muito baixo, em torno de $15 \%$. Chile (27\%) e Brasil ( $25 \%$ ) encontram-se acima da média (Chollet \& Lewis, 1997).

Como foi observado até aqui, o Brasil apresenta uma posição peculiar no que se re-

Quadro 1

Características da provisão de serviços de saúde em países da OCDE

\begin{tabular}{|c|c|c|}
\hline País & Financiamento & Prestador \\
\hline $\begin{array}{l}\text { Bélgica, França, Alemanha, } \\
\text { do } \\
\text { Áustria, Japão, Luxemburgo }\end{array}$ & Seguro social & M ix público/priva- \\
\hline Holanda & M ix seguro social/privado & Privado \\
\hline $\begin{array}{l}\text { Irlanda, Espanha, Reino U nido, Dinamarca, } \\
\text { Finlândia, Grécia, Islândia, Portugal, N oruega, Suécia }\end{array}$ & Recursos fiscais & Público \\
\hline Canadá & Recursos fiscais & Privado \\
\hline EUA, Suíça & Seguro voluntário & Privado \\
\hline Itália & Seguro social/recursos fiscais & Público \\
\hline $\begin{array}{l}\text { Austrália, Nova Zelândia } \\
\text { do }\end{array}$ & Recursos fiscais & Mix público/priva- \\
\hline $\begin{array}{l}\text { Turquia } \\
\text { do }\end{array}$ & Não há fonte predominante & M ix público/priva- \\
\hline
\end{tabular}

Fonte: 1998, <www.oecd.org>. Apud Chollet \& Lewis, 1997. 
fere à oferta combinada de serviços públicos e privados em saúde. A partir de 1990, com a criação do Sistema Ú nico de Saúde (SUS) foi tornada oficial a proposta de cobertura pública universal e integral. Paralelamente, em processo iniciado na década anterior, o setor supletivo cresce tornando-se autônomo do financiamento estatal e atingindo uma fatia de mercado bastante superior a que se constata, quer seja em países da OECD ou no grupo de países mais pobres.

No caso brasileiro, a emergência do setor supletivo passa a chamar aten ção a partir da primeira metade da década de 1980, em função da trajetória crescente de sua magnitude e, no início da década atual parece ter encontrado o ponto de estabilização, abarcando em sua clientela al go em torno de 1/4 da população brasileira. Nas seções que se seguem, após breve histórico, serão utilizados os dados da Pesquisa $\mathrm{N}$ acional de Amostra por Domicílio de 1998 (Pnad) com o objetivo de produzir evidências a respeito da segmentação do setor no caso brasileiro, assim como explicar o significado de sua expansão mais recente.

\section{O setor supletivo de assistência à saúde no Brasil: breve histórico}

Desde a década de 1960, já era possível observar no Brasil a formação de empresas médi cas com características similares às do atual setor supletivo de assistência à saúde. Porém, até o final da década de 1970, essas empresas possuíam uma clientela ainda pequena e mantinham al to grau de dependência em relação ao sistema público, estando fortemente integradas ao modelo de assistência médicoprevidenciária então vigente. No 10 Congresso Brasileiro de M edicina de Grupo, realizado em 1978, o centro dos debates foi o fortalecimento da parceria entre as empresas médicas e o Instituto $\mathrm{N}$ acional de Assistência $\mathrm{M}$ édica da Previdência Social (Inamps). Alguns números apresentados naquele congresso são bastante ilustrativos; por exemplo: naquele ano, dos 7,6 milhões de beneficiários das empresas de medicina de grupo, 4,8 milhões (61\%) eram oriundos de convênios-empresa intermediados pelo I namps.

Esses convênios, como descreve Teixeira (1989), eram estabelecidos em três instituições: uma empresa ou indústria $X$, a Previdência Social e a empresa médica. A empresa médica receberia da Previdência um valor global pelo convênio (calculado com base no número de funcionários da empresa X) passando inicialmente a ser responsável integral pelo atendimento médico desse grupo de segurados. Em uma outra forma de organização desses convênios, o empregador contratava e pagava diretamente uma empresa médica, a qual ficava responsável pela assistência à saúde de seus funcionários e dependentes, cabendo à Previdência o ressarcimento de uma dada quantia ao empregador, baseada no número de funcionários da empresa.

No início da década de 1980, o sistema médico-previdenciário de assistência à saúde, baseado na mútua dependência dos setores público e privado, mostrava sinais de esgotamento. A inoperância dos serviços prestados à população denunciava o seu fracasso. A escassez dos recursos estatais no quadro de recessão econômica do início dos anos 80, faz com que o setor privado encontre dificuldades para dar continuidade ao seu processo de acumulação, uma vez que di minuía a capacidade de absorção de sua produção por parte do Estado, seu principal comprador. A manutenção da interdependência dos setores público e privado como fundamento da estratégia de reprodução de ambos era, aparentemente, um empecilho à tentativa de superação da crise instalada (Farias, 1999).

Esse contexto setorial, aliado às pressões políticas decorrentes do processo de redemocratização, criaria o ambiente propício ao desenvolvimento de propostas de reforma do sistema público de saúde, as quais conduziriam à universal ização setor.

As empresas do setor supletivo, seguindo uma estratégia de autonomização, passaram a estabelecer relações diretas de venda de seus serviços às empresas dos setores mais dinâmicos da economia e a consumidores individuais que quisessem e pudessem contratar seus serviços. Essas empresas do setor supletivo, organizadas em diferentes modalidades (Cooperativas, M edicina de Grupo, Autogestão e Seguradoras), passaram então a absorver um grande número de profissionais de saúde, clínicas e hospitais do setor privado, alterando-se o quadro a que esses prestadores encontravam-se submetidos, deixando o Estado de ser o comprador quase exclusivo de tais serviços. Em função disso, observa-se que no final da década passada, $91 \%$ dos estabelecimentos de saú de privados utilizavam-se de 
planos de saúde no financiamento de suas atividades, e apenas $31 \%$ prestavam serviços ao SUS, conforme revela a exploração dos dados da Pesquisa de Assistência M édico-Sanitária realizada em 1999 (www.datasus. gov.br). Por certo, esta real idade comporta formas bastante variadas de vínculo ou relacionamento entre as em presas operadoras dos planos, estabel ecimentos e profissionais de saúde, contudo não seria apropriado discuti-las aqui.

I magina-se que a queda da qualidade na prestação dos serviços públicos de saúde durante a década de 1980 ten ha contribuído de forma importante para o crescimento do potencial de expansão das empresas do setor supletivo, que passaram a estabelecer relações diretas com as empresas contratantes. Faveret e Oliveira (1990), assim como M édici (1991), argumentam que naquele período o processo de expansão da clientela no sistema público de saúde não foi acompanhado de um proporcional aumento dos recursos, fato que teria deteriorado ainda mais o si stema, impondo uma forçosa racionalização dos serviços com reflexos negativos sob sua qual idade e acessibilidade. Essa linha de argumentação, embora consistente, não esgota as possibilidades de explicação do crescimento do setor supletivo. D eve-se considerar, também, a partici pação ativa das operadoras de planos e dos estabelecimentos de saúde na reestruturação da oferta no segmento do mercado de assistência à saúde.

Bahia (2001) assinala que na primeira metade da década de 1980, a quantidade de clientes de planos de saúde já se tornava expressiva, contabilizando 15 milhões de segurados segundo os registros da Associação Brasileira de M edicina de Grupo (A bramge) e da Federação das U nimed's ( não contabilizados os clientes de planos de entidades fechadas do tipo autogestão). Para a autora, já naquela década as empresas de planos de saúde consolidam-se como al ternativas assistenciais para os trabaIhadores especializados da região Sudeste.

Sob o ponto de vista patronal - grupo de suma importância em todo esse processo pode-se argumentar que o retorno das despesas com a contratação de planos de saúde para seus funcionários seria dado pela queda do absenteísmo, do maior controle sobre a força de trabalho e maior valorização do vínculo com a empresa por parte dos trabal hadores, 0 que resultaria em possíveis ganhos de produtividade. O bviamente, essas empresas contra- tantes agiam, também, sob pressão exercida pelas entidades sindicais, que passavam a demandar nas suas pautas de reivindicação a oferta de "plano de saúde" pel o empregador.

Em meados da década de 1990, o tema da regulamentação do setor supletivo da saúde penetra a agenda política mobilizando, de forma intensa, o conjunto de atores direta ou indiretamente envolvidos na produção, comercialização e consumo desses serviços de saúde. Àquel a época, a dimensão alcançada por esse mercado já ultrapassava os $30 \mathrm{mi}$ Ihões de beneficiários. Questões relativas à solvência das em presas operadoras dos planos e seguros e, principalmente, problemas relacionados aos direitos dos consumidores/ben eficiários tornavam-se cada vez mais notórios, ganhando atenção crescente nos meios de comunicação e retroalimentan do a discussão e mobilização dos atores envolvidos.

0 debate sobre a regulamentação do setor supletivo foi marcado pela dificuldade de consenso frente aos de interesses conflitantes. Pode-se identificar alguns atores importantes na década de 1990: entidades de defesa dos consumidores (IDEC, Procon, etc), M inistério Público, M inistério da Saúde, M inistério da Fazenda, Poder Legislativo, entidades de representação das empresas do setor supletivo (Abramge, Fenaseg, Confederação das Unimed's do Brasil, Ciefas, Abraspe), entidades de representação de médi cos (Associação M édica Brasileira - AM B; Consel hos Federal e Regional de M edicina) e dos hospitais (Federação Brasileira de H ospitais - FBH ). O peradoras de planos de saúde, provedores e beneficiários buscavam maximizar ganhos e minimizar perdas. A partir de 1998 o Estado inicia o processo de regulamentação do setor, por meio da lei n. 9.656/98, da medida provisória n. 1.976 e da instituição da Agência Nacional de Saúde Suplementar (AN S) no ano 2000.

Inicialmente, a legislação previa que os contratos de todos os beneficiários deveriam obrigatoriamente se adequar às novas determinações, entretanto, esta cláusula foi revogada na reedição da medida provisória $n$. 1.976 (Figueiredo et al., 2001). Dessa forma, ficou determinado que cada empresa operadora de planos deveria oferecer ao beneficiário a opção de aderir a um novo contrato que incorporasse os ben efícios assistenciais agregados pela legislação, devendo a oferta ser rei- 
terada anualmente.

A ampliação de coberturas e o estabel ecimento de parâmetros mínimos na composição dos produtos comercializados fazem com que os planos formatados, segundo à regulamentação, apresentem custos e preços mais el evados do que os planos formatados e vendidos antes da vigência da lei 9.656/98. Este fato levou a maior parte dos beneficiários a não aderir aos novos contratos ofertados. Em entrevista real izada pel os autores, em dezembro de 2002, com o diretor técnico de uma das maiores empresas de M edicina de Grupo no Brasil, este declarou que a regulamentação provocou uma el evação de preços entre $7 \%$ e $40 \%$ no valor de mensali dades de planos oferecidos pela operadoras, dependendo do perfil dos produtos que estas já comercial izavam. $\mathrm{N}$ esse cenário setorial e, em consonância com as orientações gerais do processo de reforma do estado no Brasil, foi criada no ano 2000 a Agência N acional de Saúde.

Contudo, apesar dos esforços dirigidos à regulamentação estatal dos planos de saúde, em 2000 grande parte dos usuários ainda não estava protegida pela nova legislação. Setenta por cento dos ben eficiários de planos de saúde mantinham contratos firmados no período anterior à promulgação da lei 9.656/98, segundo informações fornecida pelo entrevistado, e confirmadas pela apresentação de planiIhas de dados da ANS.

\section{A clientela do setor suplementar em saúde no Brasil}

Demonstraremos a seguir, por meio da exploração e análise dos dados da Pesquisa $\mathrm{N}$ acional por Amostra de Domicílios de 1998 (Pnad/IBGE), que o processo de reestruturação do mercado de assistência apoiou-se numa segmentação, na qual coube ao setor supletivo abarcar uma parcela substancial da clientela remanescente do antigo sistema de assistência médico-previdenciária, ou seja, trabal hadores situados no mercado formal de trabalho. É nesse grupo, particularmente, em seus estratos médios e superiores que as operadoras de planos de saúde concentram sua clientela.

Os resultados consolidados relativos ao suplemento A cesso eutilização dos servi ços de saúde da Pnad 1998 foram publicados em 2000 (IBGE, 2000), entretanto, análises mais deta-
Ihadas, como as que aqui serão apresentadas, exigem que as informações sejam trabal hadas a partir dos mi crodados da pesquisa, ou seja, do banco de dados desagregado. A manipulação direta do banco de dados permitiu preencher algumas lacunas de informação existentes na referida publicação, aprofundando assim o conhecimento sobre os usuários de planos de saúde e, indiretamente, sobre o mercado da assistência supletiva à saúde no Brasil.

A Pnad confirma a estimativa já citada na primeira parte deste texto, segundo a qual $1 / 4$ da população brasileira estaria coberto pelo setor suplementar na saúde. $N$ a pesquisa executada pelo IBGE, estima-se que $24,5 \%$ dos brasileiros possuíam planos de saúde em 1998. A análise que se segue permite qualificar esse grupo populacional, identificando tanto as características que 0 distingue do restante da população, quanto os el ementos que Ihe proporcionam uma significativa heterogeneidadeinterna.

A análise dos dados está organizada a partir dos seguintes eixos: a) caracterização das modalidades de adesão ao sistema suplementar, segundo a presença ou ausência de intermediação patronal na vinculação segurado/operadora; b) caracterização dos segurados quanto à posição no mercado de trabalho; c) caracterização dos segurados a partir da renda familiar per capita; d) distribuiç̧ão da população coberta por planos de saúde segundo as regiões do país, relacionando-a aos eixos de análise anteriormente explorados; e) por fim, uma sucinta exploração do consumo de consultas e internações hospitalares na população segurada por planos de saúde e na população SU S-dependente.

\section{Modalidades de adesão ao sistema supletivo de saúde}

Distinguiremos duas modalidades de adesão ao si stema supleti vo de saúde, utilizando como critério de demarcação o fato de o beneficiário titular do plano de saúde contar, ou não, com a participação do seu empregador no pagamento das mensal idades do mesmo. Às duas modalidades de adesão correspondem distintos segmentos da clientela das operadoras de planos de saúde. Farias (1999, 2001) refere-se a essas modalidades utilizando os termos "adesão compulsória" e "adesão voluntária", tomando a primeira como aquela derivada do vínculo empregatício, e a segun- 
da como aquela que se caracteriza pela ação privada do sujeito, que de forma livre e direta contrata no mercado o serviço de uma determinada operadora.

De forma mais ou menos similar, a distinção entre segmentos da clientel a também aparece por meio da classificação entre "seguro/ contrato coletivo" ou "seguro/contrato individual". Na linguagem do senso comum, os próprios usuários de planos de saúde ten dem a utilizar os termos "plano do emprego" e "plano particular", demarcando igualmente distintas modalidades de adesão. Cada uma dessas tipologias presta-se a usos específicos. A primeira, adequa-se a uma certa interpretação socioantropológica; a segunda é apropriada a algumas análises econômicas, jurídicas e, principalmente, atuariais; a terceira, mais simples, direta, e facilmente compreensível, constitui a forma corrente pela qual se assinala, na linguagem cotidiana, as diferentes formas de adesão. As três tipologias não se sobrepõem de forma perfeita, visto que nem sempre a presença do empregador como ente intermediário da adesão a um plano de saúde configura a existência de um "seguro/contrato coletivo". Tanto é possível a existência de um contrato coletivo sem a presença do empregador (através de associações, por exemplo), como um seguro individual pode ser custeado pelo empregador (fato corriqueiro quando 0 empregador éuma microempresa).

Os dados disponíveis não permitem mensurar a proporção de ben efi ciários segundo as modalidades de contrato individual ou coletivo, mas apenas segundo a presença ou ausência de intermediação do empregador. Para sermos mais fiéis à informação contida nos dados da Pnad, utilizaremos doravante os termos "plano pelo emprego" e "plano particular".

Verifica-se que entre os segurados de planos de saúde, $65 \%$ integram arranjos inter- mediados pelo vínculo empregatício ( plano pelo emprego), enquanto $35 \%$ contratam diretamente seus planos, e os pagam mediante desembolso próprio. A preponderância dos planos intermediados por empregadores, por si só, já constitui uma evidência de que a clientela do setor supletivo corresponde, em grande medida, àquela que outrora fora a clientela dos sistemas de assistência médicoprevidenciários.

$\mathrm{Na}$ aplicação do questionário da Pnad a pergunta Quem paga a mensalidade deste plano de saúde? (variável V 1332) era realizada apenas para a pessoa titular do plano. Essa questão possuía oito opções de resposta: 1) somente 0 empregador do titular; 2) o titular, através do trabalho atual; 3) o titular, através do trabalho anterior; 4) o titular, diretamente ao plano; 5) outro morador do domicílio; 6) pessoa não moradora do domicílio; 7) outro tipo; 8) ignorado. As opções 1 , 2 e 3 foram agregadas como "plano pelo emprego", ao passo que as opções 4, 5, 6 e 7 foram agregadas como "plano particular".

Para que pudéssemos saber, para o conjunto dos segurados (titulares + dependentes), qual a proporção dos que se beneficiavam de planos intermediados por empregadores e daqueles que possuíam plano particular, foi necessário imputar aos dependentes, na variável acima citada, a mesma resposta declarada pelo seu respectivo titular. Essa informação também poderia ser obtida utilizando-se para cálculo a média do número de dependentes de cada titular, entretanto a imputação apresenta vantagens na medida em que permite incluir os dependentes em posteriores cruzamentos da variável V1332.

Como se vê na tabela 1 , a grande maioria dos segurados adere ao si stema suplementar de saúde através de arranjos derivados do vínculo empregatício. Porém, isso não significa que essas pessoas estejam isentas de parti-

Tabela 1

Distribuição de titulares e dependentes, segundo o modo de adesão

\begin{tabular}{lccc}
\hline Tipo de adesão & $\begin{array}{c}\text { N. médio de dependentes } \\
\text { por titular }\end{array}$ & $\begin{array}{c}\text { Distribuição } \\
\text { dos titulares }\end{array}$ & $\begin{array}{c}\text { Distribuição do total } \\
\text { dos segurados }\end{array}$ \\
\hline Pelo emprego & 1,68 & $59 \%$ & $65 \%$ \\
Particular & 1,04 & $41 \%$ & $35 \%$ \\
\hline
\end{tabular}

Fonte: Pnad 1998. IBGE Tabulações especiais dos autores. 
cipação no pagamento das mensalidades, ao contrário, apenas $22 \%$ dos titulares com plano pelo emprego declararam que a mensal $i$ dade era paga integralmente pelo empregador. Embora os planos pelo emprego sejam majoritários, a proporção de planos particulares (desembolso próprio) é bastante expressiva. Esse segmento de segurados representava 8,5\% da população brasileira em 1998.

Também merece destaque a expressiva participação de segurados vinculados a institui ções de assistência a servidores públicos. Tal informação foi capturada pela seguinte pergunta, feita aos indivíduos que já haviam declarado possuir plano: Este plano de saúde é de insti tui ção de assistência de servidor público (federal, estadual ou municipal)? (variável $V 1326)$. Entre as pessoas que declaram ter plano de saúde, $25 \%$ afirmaram que o plano era de al guma instituição de assi stência a servidor público. Essas instituições são responsáveis pela assistência de $35,6 \%$ dos indivíduos que possuem planos pelo emprego.

\section{Características de trabalho dos segurados}

Cruzando-se a variável ramos da atividade econômica no trabalho principal do ano (V4716) com a variável Q uem paga a mensalidade deste plano de saúde?, constata-se que entre os titulares com plano pelo emprego $23,6 \%$ trabal ham na indústria de transforma- ção; $20,7 \%$, no ramo social (composto por serviços comunitários e sociais; serviços médicos, odontológicos e veterinários; ensino) e $15,2 \%$, na administração pública. Quanto à posição da ocupação no trabalho principal do ano (variável $V 4715$ ), 86,9\% desses titulares são trabalhadores com carteira assinada ou funcionários públicos estatutários.

Já o grupo formado pelos titulares com plano particular apresenta uma estrutura bastante distinta em relação ao grupo anteriormente analisado. Sua distribuição pelos ramos da atividade econômica revela que a maior concentração encontra-se no comércio de mercadorias com $20,6 \%$, seguido do ramo social com $17,8 \%$ e da prestação de serviços com $15,6 \%$. Em relação à posição da ocupação, apenas $40,1 \%$ declararam ser trabal hadores com carteira assinada ou funcionários públicos estatutários. Os trabal hadores por conta-própria representam $24,7 \%$, seguidos do segmento formado pelos empregadores com $19 \%$. Ressal te-se que as características de trabal ho expressas nas variáveis V 4715 e V 4716 são perguntadas apenas para as pessoas de 10 anos ou mais de idade (Tabela 2).

Quando cruzamos a variável posição na ocupação com a variável possui plano de saúde? verificamos que os grupos com maior incidência de segurados (titulares ou dependentes) são os militares com $70,9 \%$, os funcionários públicos com $66,6 \%$, os empregadores

Tabela 2

Distribuição dos titulares de planos de saúde pelos ramos de atividade econômica, segundo a modalidade de adesão

\begin{tabular}{lrrr}
\hline Ramos da atividade econômica & & Tipo de adesão \\
& Pelo emprego & $5,0 \%$ & Total \\
\hline Agrícola & $1,5 \%$ & $11,8 \%$ & $2,6 \%$ \\
Indústria de transformação & $23,6 \%$ & $3,4 \%$ & $19,8 \%$ \\
Indústria da construção & $1,8 \%$ & $1,0 \%$ & $2,3 \%$ \\
Outras atividades industriais & $3,9 \%$ & $20,6 \%$ & $2,9 \%$ \\
Comércio de mercadorias & $9,2 \%$ & $15,6 \%$ & $12,9 \%$ \\
Prestação de serviços & $6,1 \%$ & & $9,2 \%$ \\
Serviços auxiliares da atividade & & $10,8 \%$ & \\
econômica & $5,0 \%$ & $4,4 \%$ & $6,9 \%$ \\
Transporte e comunicação & $6,8 \%$ & $17,8 \%$ & $6,0 \%$ \\
Social & $20,7 \%$ & $6,4 \%$ & $19,7 \%$ \\
Administração pública & $15,2 \%$ & & $12,3 \%$ \\
Outras atividades, atividades mal & & $3,1 \%$ & $5,2 \%$ \\
definidas ou não declaradas & $6,3 \%$ & $\mathbf{1 0 0 , 0} \%$ & $\mathbf{1 0 0 , 0 \%}$ \\
Total & $\mathbf{1 0 0 , 0} \%$ & &
\end{tabular}

Fonte: Pnad 1998. IBGE. Tabulações especiais dos autores. 
com $48 \%$ e os empregados com carteira com $39,2 \%$.

\section{Características de renda dos segurados}

Para a elaboração das análises que se seguem criamos a variável renda mensal familiar per capita, dividindo a variável valor do rendimento mensal familiar exclusive agregados (V 4726) pela variável número de componentes da família exclusive agregados (V4725). A partir da nova variável foi criada uma outra, denominada estrato de renda, a qual classifica os indivíduos em três grupos, a dizer: os 10\% mais ricos; os 40\% mais pobres; os $50 \%$ da faixa intermediária. Esses três estratos foram ad otados por serem utilizados em vários estudos sobre pobreza e desigual dade no Brasil. Com isso acreditamos que tais informações possam ser mais facilmente utilizadas por estudos que se dediquem especificamente à análise das desigualdades em geral e, em particular, das desigualdades em saúde.

Primeiramente, é necessário dizer que a média aferida pela Pnad para a renda mensal familiar per capita no ano de 1998 foi de $R \$ 254,00$. Ter ciência desse valor é importante na medida em que el e nos serve de parâmetro em relação à renda dos grupos particulares que estão sendo analisados.

Comparando os indivíduos que possuem planos de saúde com aquel es que não possuem, observa-se que para o primei ro grupo 0 valor médio da renda familiar per capita éde $R \$ 569,34$, enquanto para o segundo grupo, no qual encontra-se 3/4 da população, a renda é de apenas $R \$ 153,07$. Essa diferença é bastante ilustrativa da distância social e econômica que separa os grupos e corrobora as análises que identificam as classes média e al ta como segmentos que utilizam serviços do setor suplementar, em contraste com a utilização do Sistema Ú nico de Saúde pelos segmentos de menor renda. N esse ponto interessa destacar, sobretudo, a distância que separa os rendimentos desses grupos, mas para que se tenha ao menos uma vaga referência do que os valores representavam em termos reais registre-se que o salário mínimo em 1998 era de $\mathrm{R} \$ 130,00$.

Analisando exclusivamente os segurados do setor suplementar também encontramos expressivas diferenças de renda quando comparamos o grupo que possui plano pelo emprego com o grupo que possui plano particular. Para o primeiro, o valor médio da renda mensal familiar per capita é de $R \$ 498,19$ epara o segundo al cança o valor de $R \$ 736,02$, equival ente a quase cinco vezes o valor médio aferido entre os indivíduos que não possuem seguro saúde. De uma maneira geral pode-se afirmar que a adesão ao seguro saúde através de desembolso próprio é uma prática pouco viável para segmento de menor renda. Indivíduos de renda baixa que aderem individualmente ao seguro saúde constituem um percentual residual e, como demonstrado por Farias (2001), tais adesões, quando ocorrem, freqüentemente mobilizam estratégias familiares voltadas para a proteção de membros cujo estado de saúde seja considerado vulnerável.

Utilizando a variável estrato de renda variável criada pelos autores -, foi possível descobrir que entre as pessoas que compõem o segmento dos quarenta por cento mais pobres apenas 5,1\% possuem seguro saúde, seja este particular ou pelo emprego. Em contras-

\section{Tabela 3}

Características demográficas e econômicas associadas à distribuição regional dos beneficiários de planos de saúde

\begin{tabular}{lccccc}
\hline Regiões & $\begin{array}{l}\text { \% da população } \\
\text { nacional concentrada } \\
\text { na região }\end{array}$ & $\begin{array}{l}\text { \% dos beneficiários } \\
\text { de planos de saúde } \\
\text { concentrados na região }\end{array}$ & $\begin{array}{l}\text { \% da população } \\
\text { regional coberta } \\
\text { por plano de saúde }\end{array}$ & $\begin{array}{l}\text { \% deempregados } \\
\text { com carteira na } \\
\text { população ocupada }\end{array}$ & $\begin{array}{l}\text { Renda mensal } \\
\text { familiar per capita } \\
\text { na região (R\$) }\end{array}$ \\
\hline Norte & 5,0 & 3,5 & 17,0 & 18,5 & 183,59 \\
Nordeste & 29,0 & 14,7 & 12,4 & 15,7 & 137,77 \\
Sudeste & 43,7 & 59,6 & 33,3 & 38,2 & 324,31 \\
Sul & 15,3 & 15,9 & 25,3 & 32,6 & 283,47 \\
Centro-O este & 7,0 & 6,4 & 22,5 & 25,1 & 280,65 \\
\hline
\end{tabular}

Fonte: Pnad 1998. IBGE. Tabulações especiais dos autores. 
te, no grupo formado pelos dez por cento mais ricos, $74 \%$ dos indivíduos possuem seguro saúde.

\section{Distribuição regional dos segurados}

A distribuição dos segurados do setor suplementar na saúde pelas regiões do país revela grandes desigualdades no acesso/consumo a esse tipo de serviço, quando compara-se os diferentes espaços do território nacional. O bserva-se, entre outras questões, a tradicional dicotomia entre o Sudeste e o N ordeste, que se apresentam como pólos opostos no que se refere à cobertura populacional do seguro saúde.

O Sudeste é a região onde se encontra o maior contingente de usuários de planos de saúde, concentrando $59,6 \%$ do total de segurados no país. Essa concentração deve-se tanto ao fato ser o Sudeste a região mais populosa, quanto ao elevado nível de cobertura populacional do setor supletivo nessa região. No Sudeste, 1 em cada 3 habitantes possui plano de saúde, ao passo que no N ordeste essa relação é de 1 em cada 8. A tabela 3 apresenta uma síntese das diferenças regionais mencionadas.

A região é uma unidade de análise capaz de revelar expressivas desigual dades, seja no tema em questão como em vários outros. No entanto, é importante destacar que a realidade intra-regional está longe de ser homogênea. Se por um lado as unidades da federação que compõem uma região tendem a apresentar características similares, não é menos verdade que também guardam particularidades importantes. Para exemplificar a força com que as desi gualdades podem se fazer presentes no interior da própria região é válido mencionar al guns dados relativos à proporção da cobertura dos planos de saúde segundo as unidades da federação (Tabela 4).

Os dados apresentados nas três últimas colunas da tabela 3 sugerem que a proporção da população coberta por planos de saúde por região está associada à variação observada nas variáveis pertinentes à configuração do mercado de trabalho e à renda nessas mesmas regiões. Para verificar de forma mais consistente tal associação, efetuou-se a análise a partir das U nidades da Federação, utilizando-se as variáveis: percentual da população coberta por seguro saúde na UF; percentual de empregados com carteira na população ocupada na UF; valor médio da renda mensal familiar per
Tabela 4

Diferenças intra-regionais na cobertura populacional dos planos de saúde

\begin{tabular}{lc}
\hline Regiões e UFs & $\begin{array}{c}\text { \% da população coberta } \\
\text { por plano de saúde }\end{array}$ \\
\hline Nordeste & 12,4 \\
M A & 5,9 \\
PE & 17,4 \\
Sudeste & 33,3 \\
ES & 22,8 \\
SP & 39,2 \\
\hline
\end{tabular}

Fonte: Pnad 1998. IBGE. Tabulações especiais dos autores.

capita na UF. A matriz de correlações (Tabela 5) confirma uma forte associação entre as variáveis e o gráfico da análise de regressão demonstra também a existência de linearidade nessa associação (Figura 1). Foi possível assim, construir um modelo no qual a cobertura populacional dos planos é variável dependente da dimensão do mercado formal de trabalho. Excluiu-se do modelo a variável renda pois, do ponto de vista teórico, pode-se considerá-la, também, dependente em relação ao mercado de trabal ho.

\section{Segmentação do mercado edesigual dades no consumo de serviços assistenciais}

No caso brasileiro, a segmentação de mercados implica distintos padrões de consumo dos serviços médico-assistenciais pelas respectivas clientelas. Quando anal isada a utilização dos serviços na forma de consulta médica, conclui-se que indivíduos que possuem plano apresentam indicador per capita de consultas/ano quaseduas vezes mais que aquel es que não possuem seguro. Da mesma forma, quando observa-se, nos diferentesgrupos, o percentual deindivíduosquedeclaram ter tido algumainternação hospitalar nos últimos 12 meses anteriores à pesquisa, verificase que também nesse item a população não coberta por planos desaúde apresenta menor consumo/utilização (Tabela 6).

U m assunto recorrentenas discussões sobre a segmentação demercado na assistência à saúde diz respeito à freqüência com que segurados do setor supletivo utilizam os serviços do SU S eao tipo deserviço/procedimento consumido por esses indivíduos quando recorrem ao sistema público desaúde. 
Tabela 5

M atriz de correlações

$\%$ da população coberta por seguro saúde na UF

\% da população coberta por seguro saúde na U F

$\%$ empregados com carteira na população ocupada na UF

Valor médio da renda mensal familiar per capita naUF
\% empregados com carteira na população ocupada na UF

* Correlação significante no nível de 0,01

\section{Figura 1}

Análise de regressão

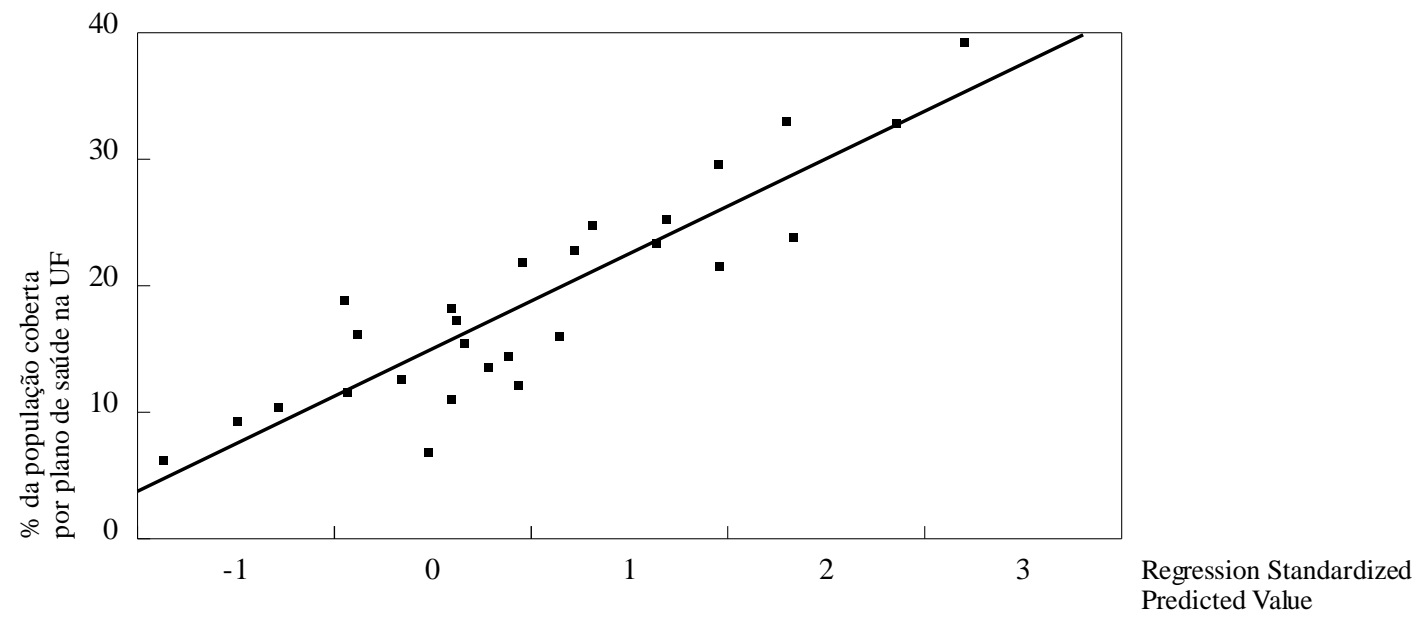

$\mathrm{R}^{2}$ ajustado $=0,791$

1,000

$0,894^{*}$

0,829*

$0,837 *$ Predicted Value

\begin{tabular}{lccccc}
\hline & \multicolumn{7}{c}{$\begin{array}{c}\text { Unstandardized } \\
\text { Coefficients }\end{array}$} & $\begin{array}{c}\text { Standardized } \\
\text { Coefficients } \\
\text { Beta }\end{array}$ & t & Sig. \\
& B & Std. Error & . & & \\
\hline (Constant) & $-0,573$ & 2,077 & & $-0,276$ & 0,785 \\
\% Empregados com carteira & 0,830 & 0,830 & 0,894 & 9,958 & 0,000
\end{tabular}

1 Dependent variable: \% da população coberta por plano de saúde na UF.

A análise dos dados procurou dimensionar a utilização de internações no SU S pelos segurados do setor supletivo, contribuindo para quese responda, ao menos em parte, à questão anteriormenteapontada. Verificou-sequeentreosindivíduosque possuem plano de saúde, etiveram al gumainternação nos 12 meses anterioresà pes- quisa, 14\% declararam que aúltima internação fora realizada através do SUS. Vale destacar que, para os segurados situados no estrato de renda correspondenteaos $40 \%$ mais pobres, essepercentual alcança $33,7 \%$ ao passo que entreos $10 \%$ mais ricos atinge apenas $5,7 \%$. 0 fato indica que os usuários do primeiro grupo provavelmente 
Tabela 6

Consumo/utilização de serviços médicos (consultas e internações)

\begin{tabular}{lcccc}
\hline Indicadores de consumo & $\begin{array}{c}\text { Beneficiários de planos } \\
\text { de saúde(todos) }\end{array}$ & $\begin{array}{c}\text { Beneficiários de planos } \\
\text { de saúde (pelo emprego) }\end{array}$ & $\begin{array}{c}\text { Beneficiários de planos } \\
\text { de saúde (particular) }\end{array}$ & $\begin{array}{c}\text { População não vinculada } \\
\text { a planos de saúde }\end{array}$ \\
\hline $\begin{array}{l}\text { consulta per capita } \\
\text { (12 meses) }\end{array}$ & 3,1 & 2,8 & 3,5 & 1,75 \\
\% deindivíduos & & 7,3 & 8,7 & 6,6 \\
internados em 12 meses & 8,0 & & & \\
\hline
\end{tabular}

Fonte: Pnad 1998. IBGE. Tabulações especiais dos autores.

possuíam planos mais restritivos, principalmentese considerarmosque, no período investigado pela Pnad, os pacotes mínimos de serviçosque deveriam ser ofertados nos produtos comercializados pelas empresas operadoras de planos ainda eram alvo de contestações, eo processo deregulação vivia um momento embrionário.

Embora a utilização de internações SU S pelos beneficiários de planos não possa ser considerada residual, nota-sequea utilização da rede hospital ar vinculada às em presas operadorasé absolutamente majoritária entre os segurados. Considerando todos os indivíduos que declaram ter tido internação no SUS, os segurados do setor supletivo representavam 6,3\%. É plausível supor que, em decorrência da regulamentação que, entre outras medidas, estabelece padrões mínimos de cobertura para os produtos comercializados, a utilização deinternações SUS por segurados do setor supletivo tenha diminuído nos últimos anos.

\section{Conclusão}

Este estudo mostra a particularidade do caso brasileiro em relação à forma como interagem no mercado o setor público e privado em saúde. Como foi visto, em países desenvolvidos, com exceção dos EU A, o setor privado desempenha uma função complementar aos sistemas públicos atuando em faixas muito específicas e correspondendo a exigências de consumo de setores de altas ren das.

Procurou-se também apresentar as principais fal has de mercado relatadas pela literatura, no campo da economia da saúde, tais como: risco moral, seleção adversa e sel eção de risco. Na ausência de uma ação regulatória do Estado, essas fal has se transformam em graves entraves ao acesso à assistência, principal- mente em países onde o seguro privado tornase respon sável pela cobertura de uma ampla parcela da população.

Sob o ponto de vista dos sistemas de assistência à saúde, os dados permitem afirmar que o mercado brasileiro encontra-se claramente segmentado - os sub-sistemas público eprivado apresentando clientelas quase exclusivas, determinadas por características detrabal ho e renda. Esta conclusão está amparada na evidência demonstrada pela forte associação das variáveis de renda familiar per capita e posição no mercado de trabal ho, com a variável que registra a magnitude do setor supletivo. A matriz de correlações e o resultado da análise de regressão constituem boas indicações para a comprovação desse fenômeno. I gual mente, os dados sobre o perfil de consumo das distintas clientel as corroboram o argumento da segmentação do mercado.

Não obstante, fundamental destacar a importância do SU S como provedor de serviços para $3 / 4$ da população brasileira, lembrando que estrato de renda formado pelos $40 \%$ mais pobres, apenas $5,1 \%$ dos indivíduos possuem plano de saúde. Em todas as regiões do país o sistema público é majoritário, em especial, nas regiões $\mathrm{N}$ orte e $\mathrm{N}$ ordeste onde o setor suplementar ainda é pouco desenvolvido, devido às condições socioeconômicas locais.

Há várias indagações freqüentes para as quais os dados disponíveis ainda não permitem respostas adequadas, como por exemplo, o grau de qualidade e resolubilidade dos segmentos público e privado. Contudo, a Pnad oferece ampla margem de possibilidades de análises acerca de características socioeconômicas dos segurados no setor suplementar em saúde, al ém de possibilitar estudos variados a respeito do acesso eutilização de serviços de saúde por parte da população em geral. 


\section{Referências bibliográficas}

Agência N acional de Saúde Suplementar 2002. Regulação e saúde: estrutura, evolução e perspectivas da assistência médica suplementar. Ministério da Saúde/ANS, Rio de Janeiro.

Arrow KJ 1963. Uncertainty and the welfare economics of medical care. American Economic Review 53:941-973.

Arrow KJ 1985. Theoretical issues in health insurance. In KJ Arrow. Collected papers of Kenneth J. A rrow volume 6: Applied Economics. Havard University Press, Cambridge.

Bahia L 2001. Planos privados de saúde: luzes e sombras no debate setorial dos anos 90. Revista Ciência e Saúde Coletiva 6(2):329-340.

Chollet DJ \& Lewis M 1997. Private insurance: principles and practice. In GJ Schieber. Innovations in health care, proceedings of a W orld Bank Conference. M arch 10-11, 1997. W orld Bank. (Series WB Discussion Papers, 365).

Congresso Brasileiro de M edicina de Grupo 1978. Anais do 10 Congresso Brasileiro de M edicina de Grupo. DAG, São Paulo.

Cutler DM \& Zeckhauser RJ 1999. The anatomy of health insurance. NBER Working Paper 7.176. Disponível em <http://www.nber.org/paperS/W 7176>.

Farias LO 2001. Estratégias individuais de proteção à saúde: um estudo da adesão ao sistema de saúde suplementar. Revista Ciência e Saúde Coletiva 6(2):405-416.

Farias LO 1999. A desão voluntária aos planos de saúde em camadas populares. Dissertação de mestrado. Escola N acional de Saúde Pública/Fiocruz, Rio de Janeiro.

Faveret Filho P \& Oliveira PJ 1990. A universalização excludente: reflexões sobre as tendências do sistema de saúde. Dados Revista de Ciências Sociais 33(2):257-283.

Figueiredo LF, Andréa LB \& Checchia CM A 2001. M ercado de atenção supletiva e regulamentação. In PR Barbosa. Autogestão em saúde: volume 1. Fiocruz, Rio de Janeiro.

HSIAO W 2000. What should macroeconomists know about health care policy? A primer, I M F. Working Paper 136. Disponível em <http://www.imf.org/external/pubs/ft/wp/2000/wp00136.pdf>.

IBGE 2000. Acesso e utilização de serviços de saúde 1998. IBGE, Rio de Janeiro.

IBGE 2000. Estatísticas da saúde: assistência médicosanitária 1999. IBGE, Rio de Janeiro.

Médici AC 1991. A medicina de grupo no Brasil. Organização Pan-Americana de Saúde, Brasília. (Série Desenvolvimento de Políticas Sociais, 1 ).

M usgrove P 1996. Public and private roles in health. W orld Bank Discussion Paper 339. Disponível em <http:// www-wds.worldbank.org/servlet/WD $\mathrm{S}$ C $0 \quad n$ t e $n$ t $S$ e $r \quad v$ e $r$ / WDSP/IB/1996/08/01/000009265_3961219094216/ Rendered/PDF/multiopage. pdf >.

Teixeira SM F 1989. Política de saúde na transição conservadora. Londrina, CEBES. Revista Saúde em Debate (26):42-53

Artigo apresentado em 21/10/2002

Aprovado em 27/11/2002

V ersão final apresentada em 3/2/2003 